\title{
2-Thiazoline Amide Derivatives as Liquid Crystals
}

\author{
Juliana M. F. M. Schneider, ${ }^{*}$ Paulo H. Schneider and Aloir A. Merlo
}

Instituto de Química, Departamento de Química Orgânica, UFRGS, Av. Bento Gonçalves, 9500, Campus do

Vale, Porto Alegre, RS, Brasil, 91501-970.

*e-mail corresponding author: Juliana@iq.ufrgs.br

Keywords: 2-thiazoline, self-assembling amides, chiral liquid crystals

\section{INTRODUCTION}

In recent years, promising materials incorporating five or six membered heterocyclic derivatives as core unit or terminal moiety have attracted great attention ${ }^{1}$.The heterocyclic unit has the ability to impart lateral and/or longitudinal dipoles coupled with changes in molecular shapes. On the other hand, ferroelectric liquid crystals have attracted special interest because these materials exhibit a large spontaneous polarization and a fast response to an applied electric field ${ }^{2}$. Compounds containing the 2-thiazolinic ring may aggregate both parameters to the final mesogens since they display an asymmetric carbon in their structure. However, these compounds have not been reported yet as liquid crystals materials although they may afford an interesting possibility for the study of mesomorphic behavior, as different groups can be inserted at positions 2 and 4 of the ring. Thus, we report in this work the design and synthesis of a new class of chiral liquid crystals containing the 2-thiazoline heterocycle (figure 1) as well as the initial studies of their mesomorphic behavior.

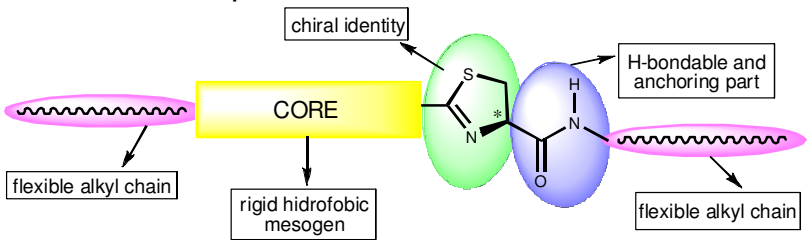

Figure 1: Basic skeleton of the derivatives

\section{RESULTS AND DISCUSSION}

We envisioned the obtention of amide derivatives in order to observe the influence of hydrogen bonding ${ }^{3}$ on self-organization of the mesogens. The synthetic route begins with ciclization of nitriles derivatives (1) with the easily available amino acid L-cysteine (scheme 1).

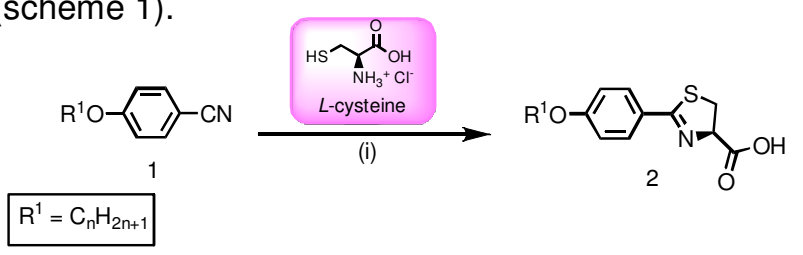

(i) $\mathrm{NaHCO}_{3}, \mathrm{MeOH}, 60^{\circ} \mathrm{C}, 90 \mathrm{~h}, \mathrm{pH}=6,(51 \%)$.

Scheme 1: Ciclization of thiazoline ring
With these key intermediates (2) in hands, convertion to the corresponding amides was achieved via boronic acid catalisis ${ }^{4}$ (scheme 2 ).

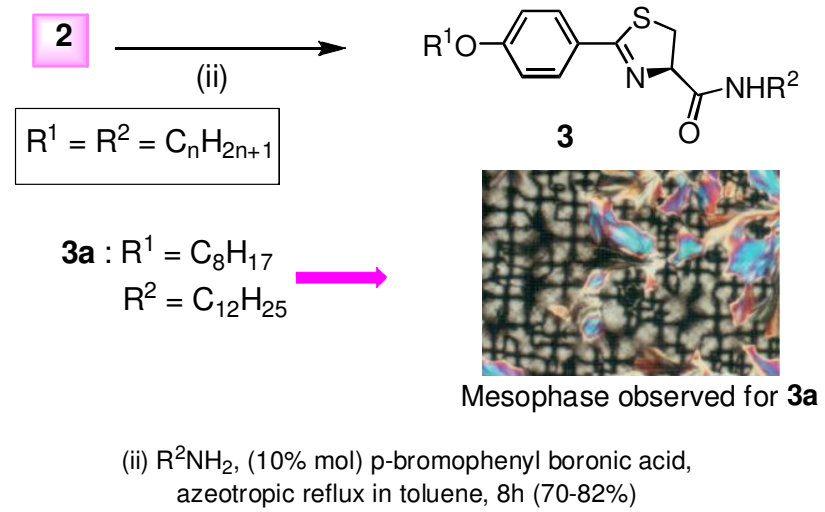

Scheme 2: Obtention of amide derivatives

This methodology afforded the amide products with excellent yields. It is noteworthy that the represented compound (3a) showed a slight monotropic mesomorphic behavior, with a narrow range of temperature. These results are being improved, with incorporation of biphenyl and/or tolane groups in both ring positions ( 2 and 4 ) of the thiazoline amides. Thus, enhancement of this mesomorphic behavior will be achieved via higher molecular anisotropy. The nature of the mesophase of $\mathbf{3 a}$ is under analysis.

\section{CONCLUSION}

Design and synthesis in two steps of a new class of 2-thiazoline heterocycles as potential liquid crystals compounds were reported in this work. More studies exploring the molecular structure are ongoing, as well as the evaluation of possible ferroelectric behavior.

\section{ACKNOWLEDGEMENTS}

CNPq, INCT-CMN, FAPERGS, PROCAD-CAPES

\section{REFERENCES}

(a) Lai, C. K. et. al. Tetrahedron, 2011, 67, 114. (b) Gallardo, H. et. al. Tetrahedron Lett. 2009, 50, 905.

${ }^{2}$ Collins, P. J. Journal of the Franklin Institute, 2005, 342, 599.

${ }^{3}$ Tschierske, C. et. al. J. Mater. Chem. 2011, 21, 5307.

${ }^{4}$ Marcelli, T. Angew. Chem. Int. Ed. 2010, 49, 684. 